\section{SIR WILLIAM THOMSON ON NAVIGATION ${ }^{1}$}

$\mathrm{POPULAR}$ lectures rarely contain much that deserves repetition or notice in a review. But when the lecturer is Sir William Thomson and his subject navigation, we may be sure that we shall hear something that we have not heard before, and that we should hear, if we wish to keep abreast of the advance of nautical science. When a reformer contents himself with merely making suggestions and leaving it to others to test them, his work is comparatively easy and its results are proportionally valueless. The suggestions of Sir W. Thomson have the very specinl merit that they are submitted to a practical test before he gives them utterance, and after he has done so he is far from considering his connection with them over. Every part of every crude idea or novel appliance is submitted to a searching process of natural selection which must cost the author as much labour as to watch it gives the onlooker pleasure, and those who see only the final survival of the fittest cannot form anything like a just conception of the time and pains which have been bestowed on the rejection of the less fit.

We cannot here find space to notice those parts of the lecture which are the reproduction of old and received truths, interesting though these are by virtue of their skilful dressing. We must pass on at once to mention one or two points which are either in themselves new, or which have as yet failed to secure the recognition they deserve.

The first important novelty we come to is the discovery by Mr. Hartnup, astronomer to the Harbour Board of Liverpool, of a system of rating chronometers, which gives an almost perfect means of compensating for change of rate due to change of temperature. It had long been known that no compensation balance could be made to keep time correctly through wide ranges of temperature :-

"Thus the best chtonometers of the best makers in modern times are practically perfect only within a range of $5^{\circ}$ or $10^{\circ}$ Fahrenheit on each side of a certain temperature, infinitely near to which the compensation is perfect in the individual chronometer.

"The temperature for which the compensation is perfect, and the amount of deviation from perfection at temperatures differing from it are different in different chronometers. Mr. Hartnup finds that at the temperature for which the compensation is peffect, the chronometer goes faster than at any other temperature, and that the $\mathrm{ra}^{+} \mathrm{e}$ at any other temperature is calculated with marvellous accuracy (if the chronometer be a good one) by subtracting from the rate at that critical temperature the number obtained by multiplying the square of the difference of temperature by a certain constant coefficient."

Two chronometers recently carried from Liverpool to Calcutta, when rated on Mr. Hartnup's plan, gave a mean error of six seconds, while by the ordinary method the reckonings of Greenwich time from them differed by 4 minules 35 seconds. The navigator could easily secure the advantages of 'Mr. Hartnup's system by noticing the temperature of his chronometer-case daily, and entering a few figures in a note-book. His work would be much facilitated if the thermometer used were graduated to squares of numbers of degrees from the temperature of maximum rate.

The lecturer discusses at considerable length various modifications of the pressure-log, the invertion of $\mathrm{Mr}$. J. R. Napier and Mr. Berthon, the principle of which is to measure the speed of the ship by observing to what height a column of water rises in a vertical tube; the

I Navigation. A Lecture delivered urder the atispices of the Glasgow Science Lectures Association. By. Sir William Thomson, D.C.L., LL.D., F.R.S., Professor of Natural Philoso'phy in the University of Glasgow, and Fellow of St. Peter's College; Carnbridge: (London and Glasgow William Collins, Sons, and Company, 1876 .) bottom end of which dips into the sea and faces forwards. It shows the ship's velocity through the water at any instant, instead, like all other logs, of telling the distance run during a known length of time. The latter piece of information is what is chiefly wanted for the purposes of ordinary navigation, but the former could not fail to be of immense use in the navy when ships are sailing in squadron. Even now, a rough approximation to a knowledge of velocity is got in the navy by the use of indicators showing the number of revolutions per minute made by the screw, and these satisfy very imperfectly the requirements of the case, as appears from the evidence given at the court martial on the loss of the Vanguard. The Admiral signalled to the squadron that his ship was about to go at thirty-three revolutions, which he afterwards explained to mean that he desired the squadron to go as nearly as possible at a speed of seven knots. Had each of the ships been provided with a pressure log, he might at once have given an order of whose meaning there could have been no possible doubt, and which it would have been perfectly easy for every ship to obey.

The taking of soundings to determine the depth is one of the most important of nautical operations. In surveys of the ocean's bed and for guidance in cable laying, soundings have to be made in great depths, often of several thousand fathoms. The trouble and time involved in taking a deep-sea sounding have been greatly reduced by Sir W. Thomson by the substitution of a single steel pianoforte wire for the hemp rope formerly used as a sounding line. The advantage of the wire is the comparatively small resistance it meets with in passing through the water. When hemp rope is used for sounding in deep water a weight of three or four hundred pounds must be attached to it, and even then it descends very slowly. When it reaches the bottom the weight is detached by a trigger and is therefore lost. When wire is used a weight of about thirty pounds suffices; it descends very much more rapidly, and there is nothing to prevent its recovery each time. For very small depths such as are met with in the immediate neighbourhood of land, the hand lead is convenient and sufficient, but there is a third class of soundings, those which are (or should be) made in depths of about twenty fathoms and upwards when a ship is approaching land. To be able to take "flying" soundings-that is, to find the depth without stopping the ship-in any depth from 20 to 150 fathoms, is a matter of the greatest possible importance in ordinary navigation. Sir W. Thomson has succeeded in making it easy to do this, by the aid of his pianoforte wire in combination with another apparatus which he described at the recent meeting of the British Association. This consists of a pressure gauge of very simple construction, which is attached close to the end of the sounding-line, and which, by registering the maximum pressure to which it has been subjected during immersion, registers the 1naxim:m depth it has attained. This indieation is of course quite independent of the length of wire out, and is not affected by the fact that the ship is in motion. The pressure gauge consists of a small glass tube, of about $\frac{1}{10}$ inch bore, open at the lower end, but closed at the top. As this descends, the water rises in the tube compressing the column of air. In order that a permanent record may be left of the maximum height : to which the water rises, the interior of the tube is coated along its whole length with starch, in which red prussiate of potash has been dissolved, and just at the mouth of the tube are placed a few. crystals of sulphate of iron, which are held in position by an outer guard tube. The water which rises in the tube carries with it a little sulphate of iron in solution, and so leaves a permanent record of its height by staining the tube with Prussian blue. The system of sounding by wire has now had abundant trial, and its success is thoroughly established. Its author was, no doubt, quite within the 
limits of safe prophecy when he declared to the British Association in Glasgow that the old system of deep-sea sounding by hemp rope had done its last work on board the Challenger.

In proceeding to speak of astronomical navigation the author begins by giving a series of definitions which differ from those commonly given, by being based on no assumption as to the figure of the earth, so that they "designate in each case the thing found when the element in question is determined by actual observation." Thus the latitude of a place is defined as the altitude there of the celestial pole. After a flying shot at the British Statute mile, whose existence " is an evil of not inconsiderable moment to the British nation," he goes on to describe the various means of deducing a ship's place from observations of the heavenly bodies, giving the place of honour to Sumner's method, of the merits of which we had recent occasion to speak (NATURE, vol. xiv. p. 346).

To communicate information from ship to ship by signals is an object of first importance to the sailor. By day, in clear weather and with skilful men, the system of flag and semaphore signals at present in use in the navy is very complete and effective. By night, in clear weather; Capt. Colomb's method of flashing signals has been successfully used in the British navy for nearly twenty years, but its adoption has not been nearly so general as properly to meet the requirements of the case. On this point Sir W. Thomson says:-

"The essential characteristic of Capt. Colomb's method, on which its great success has depended, consists in the adoption of the Morse system of telegraphing by rapid succession of shorts and longs; 'dots' and 'dashes,' as they are called; and, I believe, its success would have been still greater, certainly its practice would have been by the present time much more familiar to every officer and man in the service than it is now, had not only the general principle of the Morse system but the actual Morse alphabet for letters and numerals been adopted by Capt. Colomb. A modification of Capt. Colomb's system, which many practical trials has convinced me is a great improvement, consists in the substitution of short and long eclipses for short and long flashes. In the system of short and long eclipses, the signal lamp is allowed to show its light uninterruptedly until the signal com. mences. Then groups of long and short eclipses are produced by a movable screen, worked by the sender of the message, and read off as letters, numerals, or code signals by the receiver or receivers. ... Whenever the light of a lamp suffices, the eclipse method is decidedly surer, particularly at quick speeds of working, than the flash method, and it has besides the great advantage of showing the receivers exactly where to look for the signals when they come, by keeping the signal lamp always in view in the intervals between signals, instead of keeping it eclipsed in the intervals as in Colomb's method."

Is it too much to hope that before very long a knowledge of the Morse alphabet may form part of the elementary education of every boy and girl in the kingdom? Only then can the public awaken to a sense of the many uses to which such a knowledge could be put.

But there is a third set of conditions where signalling is more necessary as well as more difficult than in either of the other two. In fogs, by day or night, visible signals have to be given up as useless, and audible ones take their place. We may utilise Colomb's code or the Morse alphabet by giving short and long blasts on a steam whistle or fog-horn.

"But here again a very great improvement is to be made. Use instead of the distinction between short and long the distinction between sounds of two different pitches, the higher for the 'dot,' the lower for the 'dash.' Whether in the steam whistle or the fog-horn a very sharp limitation of the duration of the signal is scarcely attainable. There is, in fact, an indecision in the begin ning and end of the sound, which renders quick and sure Morse signalling by longs and shorts impracticable, and entails a painful slowness, and a want of perfect sureness, especially when the sound is barely audible. Two foghorns or two steam-whistles, tuned to two different notes, or when the distance is not too great, two notes of a bugle or cornet may be used to telegraph words and sentences with admirable smartness and sureness. Five words a minute are easily attainable. This method has the great advantage that, if the sounds can be heard at all, the distinction between the higher and the lower, or, as we may say for brevity, 'acute' and 'grave,' is unmistakable : whereas the distinction between long and short blasts is lost, or becomes uncertain, long before the sound is inaudible."

To produce powerful blasts of sound differing from each other in pitch the Americans have devised an instrument which is much more effective than the fog-horn or steam-whistle. By the irony of fate sirens are now enlisted in the service of humanity, and no longer lure sailors to destruction. The reform in their morals, how. ever, has been fatal to their romantic charm, for now they are "driven at a uniform rate by clockwork, and the blast is supplied from a steam boiler." But is the change to be regretted when we hear that:-

"Short and long blasts of the siren might be advantageously substituted for short and long blasts of the steam whistle, but much more advantageously short blasts of two sirens on the same shaft, or on two shafts geared together, sounding different notes, acute note for the short, grave note for the long. The rapidity and the ready dis. tinctiveness of character of the two notes will then be such that every officer and man will habitually recognise evolutional signals and signals for course and speed, just as in skirmishing every officer and private knows the bugle calls; and the signal-book will be no more needed on the bridge of a ship of war than on the saddle of a field officer. When the admiral desires to alter speed or course for the fleet, his order will be given to the whole fleet simultaneously, and very nearly as fast as he can speak it to his flag captain, and then instantly (without waiting to open signal-books) the other ships will, one after another in order, each in replying give the "understand,' repeat the numbers expressing course and speed, and make her pennant. In as many quarter-ninutes as there are ships under his command, the order will have been thus securely acknowledged by every one of them, and the admiral will sound his signal announcing that the order commences to take effect. Nothing short of this in quickness and sureness of ordering the movements of a fleet ought for a moment to be thought of as tolerable, when it is certain (as it assuredly is) that so much is readily attainable."

We have quoted this part of the lecture at considerable length, for we have a strong conviction of its high practical value. The collision between the Monarch and the Raleigh in Besika Bay, which has happened since the lecture was published, serves to point Sir W. Thomson's moral. We are told that when the squadron was in three lines steaming at about five knots an hour, a signal was made to alter the course, which "from some unexplained cause" was misunderstood by two of the ships-- the Triumph and the Invinuible. This brought the latter across the bows of the Monarch, which then stopped and reversed engines, but the Raleigh, astern of the Monarch, kept on her course, the result being a collision, which was fortunately much less serious in its consequences than the costly Vanguard experiment, of which this one bid fair to be a repetition. That the signal was misunderstood, not by all the ships, and yet by two of them, seems to prove that much blame cannot be attached either to those who made it, or to those who read it ; it is, in fact, the system that is at fault. 